\title{
PENGARUH KINERJA KEUANGAN DAN TINGKAT KEBIJAKAN UTANG TERHADAP NILAI PERUSAHAAN DENGAN GROSS DOMESTIC PRODUCT SEBAGAI VARIABEL MODERATOR PADA PERUSAHAAN PERTAMBANGAN YANG TERDAFTAR DI BEI PERIODE 2015-2017
}

\author{
Stella Febriyani Irsan ${ }^{1}$, Jonnardi ${ }^{2}$ \\ ${ }^{1}$ Magister Akuntansi, Universitas Tarumanagara Jakarta \\ Email: stellafebriyani02@gmail.com \\ ${ }^{2}$ Dosen Fakultas Ekonomi, Universitas Tarumanagara Jakarta
}

Masuk : 23-08-2019, revisi: 23-08-2019, diterima untuk diterbitkan : 30-10-2019

\begin{abstract}
ABSTRAK
Penelitian ini bertujuan untuk mengetahui pengaruh kinerja keuangan dan tingkat kebijakan utang terhadap nilai perusahaan dengan gross domestic product sebagai variabel moderator pada perusahaan pertambangan yang terdaftar di BEI periode 2015-2017. Penelitian ini dijalankan didasari atas pertumbuhan ekonomi pada kuartal I2018 yang tercatat sebesar 5,06\%. Namun, dari lapangan usahanya, sektor pertambangan mengalami pertumbuhan paling kecil di level 0,74\%. Meski tumbuh paling kecil, sektor pertambangan mulai bangkit dari keterpurukannya dari periode yang sama tahun lalu yang tumbuh negatif $-1,22 \%$. Hal ini menunjukkan bahwa saat ini, industri pertambangan merupakan salah satu industri yang belum mampu menunjukkan kestabilan di pasar. Metode penelitian yang digunakan dalam penelitian ini adalah metode penelitian kuantitatif dengan pendekatan asosiatif. Metode pengolahan data yang digunakan dalam penelitian ini adalah regresi data panel dengan pendekatan moderated regression analysis. Dari hasil penelitian ditemukan bahwa kinerja keuangan tidak berpengaruh terhadap nilai perusahaan, dan tingkat kebijakan utang berpengaruh positif signifikan terhadap nilai perusahaan. Gross domestic product tidak memoderasi pengaruh kinerja keuangan terhadap nilai perusahaan, namun Gross domestic product memperkuat pengaruh tingkat kebijakan utang terhadap nilai perusahaan pertambangan yang terdaftar di BEI periode 2015-2017. Saran yang dapat diberikan adalah penambahan jumlah tahun penelitian agar penelitiannya mendapatkan hasil yang lebih akurat, lebih luas, terpercaya, dan mampu untuk menggambarkan keadaan dengan lebih jelas, serta menambahkan jumlah variabel independen yang dapat digunakan yang dapat mempengaruhi nilai perusahaan seperti praktik manajemen laba, Good Corporate Governance, Risiko bisnis, dan sebagainya.
\end{abstract}

Kata Kunci: Kinerja Keuangan, Tingkat Kebijakan Utang, Nilai Perusahaan, Gross Domestic Product.

\begin{abstract}
This study aims to determine the effect of financial performance and the level of debt policy on the value of companies with gross domestic product as a moderating variable in mining companies listed on the Indonesia Stock Exchange in the 2015-2017 period. This research was carried out based on economic growth in the first quarter of 2018 which was recorded at 5.06\%. However, from the business field, the mining sector experienced the smallest growth at the level of $0.74 \%$. Despite growing the smallest, the mining sector began to rise from its downturn from the same period last year which grew negative $-1.22 \%$. This shows that currently, the mining industry is one industry that has not been able to demonstrate stability in the market. The research method used in this study is a quantitative research method with an associative approach. The data processing method used in this study is panel data regression with a moderated regression analysis approach. From the results of the study found that financial performance has no effect on firm value, and the level of debt policy has a significant positive effect on firm value. Gross domestic product does not moderate the effect of financial performance on firm value, but Gross domestic product strengthens the influence of the level of debt policy on the value of mining companies listed on the Indonesia Stock Exchange in the 2015-2017 period. Suggestions that can be given are increasing the number of years of research so that the research gets results that are more accurate, more extensive, reliable, and able to describe the situation more clearly, as well as adding the number of independent variables that can be used that can affect company value such as earnings management practices, Good Corporate Governance, Business risk, and so on.
\end{abstract}

Keyword : Financial Performance, Debt Policy Level, Company Value, Gross Domestic Product. 


\section{PENDAHULUAN}

\section{Latar Belakang}

Industri pertambangan saat ini merupakan salah satu industri yang cukup disorot oleh pemerintah Indonesia. Hal ini terbukti dari Pertumbuhan ekonomi pada kuartal I-2018 yang tercatat sebesar $5,06 \%$. Namun, dari lapangan usahanya, sektor pertambangan mengalami pertumbuhan paling kecil di level $0,74 \%$. Meski tumbuh paling kecil, sektor pertambangan mulai bangkit dari keterpurukannya dari periode yang sama tahun lalu yang tumbuh negatif $-1,22 \%$. Hal ini menunjukkan bahwa saat ini, industri pertambangan merupakan salah satu industri yang belum mampu menunjukkan kestabilan di pasar.

Melihat dari belum konsistennya pertumbuhan industri pertambangan di Indonesia, membuat industri pertambangan perlu untuk memperhatikan hal-hal menyangkut nilai perusahaan, karena nilai perusahaan merupakan salah satu acuan masyarakat untuk membeli saham perusahaan. hal ini juga sejalan dengan informasi yang didapatkan dimana saat ini memang harga saham-saham tambang merosot. Indeks saham tambang bahkan mencetak kinerja paling buruk, merosot 5,15\% sepanjang Agustus 2018. Melihat dari keterkaitan tersebut, maka memang nilai perusahaan adalah salah satu hal yang penting untuk diteliti.

Nilai perusahaan berkaitan erat dengan teori signalling dalam akuntansi. Teori Sinyal menurut Scott (2012:475) yang memiliki banyak informasi yang lebih baik akan terdorong untuk menyampaikan informasi tersebut kepada investor. Perusahaan dapat meningkatkan nilai perusahaan melalui pelaporannya dengan mengirim sinyal melalui laporan keuangan tahunan. Tanggapan investor terhadap sinyal positif dan negatif sangat berpengaruh terhadap kondisi pasar, mereka akan bereaksi dengan berbagai cara dalam menanggapi sinyal tersebut. Keterkaitan antara teori signalling dengan penelitian ini adalah dimana nilai perusahaan merupakan salah satu bentuk signalling theory yang diterapkan dengan baik.

Dalam penelitian ini, nilai perusahaan akan diukur dengan Tobin's Q. Tobin's Q dikembangkan oleh Professor Tobin (Weston dan Copelan, 2008:243). Rasio ini merupakan konsep yang berharga karena menunjukkan estimasi pasar keuangan saat ini tentang nilai hasil pengembalian dari setiap investasi. Semakin tinggi nilai Tobin's Q, maka menunjukkan sebuah perusahaan berhasil memaksimalkan investasi yang dimiliki atau didapatkan baik dari modal ataupun dari utang.

Penelitian ini akan mencoba meneliti faktor-faktor yang dapat memengaruhi nilai perusahaan yang diproksikan dengan Tobin's Q. Faktor-faktor yang diteliti meliputi tingkat kebijakan utang dan kinerja keuangan.

Faktor pertama yang diduga dapat memengaruhi nilai Tobins' $Q$ adalah kinerja keuangan. Kinerja keuangan dalam penelitian ini diproksikan dengan retained earnings atau laba di tahan. Semakin tinggi tingkat laba yang di tahan perusahaan, menunjukkan perusahaan memiliki laba yang sangat besar. Dengan keadaan tersebut, maka cenderung perusahaan akan melakukan pembagian dividen pada periode tersebut. Dengan pembagian dividen tersebut, membuat pasar merasa perusahaan sangat memperhatikan kesejahteraan pemegang saham dan akan berkemungkinan meningkatkan nilai perusahaan. Oleh karena itu, diduga, kinerja keuangan yang diproksikan dengan retained earnings berpengaruh positif terhadap nilai perusahaan. Hal ini sesuai dengan hasil penelitian yang dijalankan oleh Yemi dan Seriki (2018) yang menyatakan bahwa kinerja keuangan berpengaruh positif signifikan terhadap nilai perusahaan dan 
berlawanan dengan penelitian Ater et al (2018) yang menyatakan bahwa kinerja keuangan berpengaruh negatif terhadap nilai perusahaan dan bertentangan dengan hasil penelitian.

Faktor kedua yang diduga dapat memengaruhi nilai Tobin's Q adalah tingkat kebijakan utang. Tingkat kebijakan utang dalam penelitian ini diproksikan dengan leverage atau pembagian antara tingkat hutang dengan tingkat ekuitas perusahaan. Semakin tinggi nilai leverage sebuah perusahaan, maka akan semakin tinggi juga tingkat hutang perusahaan, namun dengan tingkat hutang yang tinggi, maka perusahaan akan menghasilkan produksi yang lebih besar dan secara tidak langsung akan meningkatkan profit perusahaan. Dengan semakin tingginya profit perusahaan, maka pasar akan melihat kinerja perusahaan tersebut dan akan meningkatkan nilai perusahaan. Oleh karena itu, diduga, Tingkat kebijakan utang berpengaruh positif terhadap nilai perusahaan. hal ini didukung dengan penelitian yang dijalankan oleh Singh et al (2018) yang menyatakan bahwa memang leverage berpengaruh positif terhadap nilai perusahaan, namun bertentangan dengan hasil penelitian Yemi dan Seriki (2018) yang menyatakan leverage berpengaruh negatif terhadap nilai perusahaan.

Menurut penelitian yang dijalankan oleh Ater et al (2017) dijelaskan bahwa pengaruh kinerja keuangan dan tingkat kebijakan utang dapat dimoderasi oleh satu variabel makro yaitu Gross Domestic Product. Gross Domestic Product merupakan perhitungan jumlah produk atau jasa yang dihasilkan suatu negara dalam periode tahunan. Apabila tingkat Gross Domestic Product sebuah negara meningkat disaat tingkat kebijakan utang perusahaan tinggi, maka hal ini akan mendorong peningkatan nilai perusahaan karena hal ini menunjukkan bahwa hutang yang digunakan oleh perusahaan berhasil dimaksimalkan untuk memproduksi produk atau jasa sehingga meningkatkan Gross Domestic Product. Selanjutnya, untuk Kinerja keuangan, apabila Gross Domestic Product mengalami peningkatan di saat kinerja keuangan juga tinggi, maka akan melemahkan pengaruh dari kinerja keuangan karena masyarakat akan tetap optimis pada sebuah perusahaan yang dapat menghasilkan produksi yang tinggi.

Alasan dari penggunaan Gross Domestic Product dalam penelitian ini dikarenakan Gross Domestic Product sangat berkaitan dengan perusahaan pertambangan dikarenakan pendapatan dari industri pertambangan yang sangat relatif masih rendah. Kontribusi industri ekstraktif terhadap total PDB pada 2016 adalah sebesar 7 persen, turun dibandingkan posisi 2015 yaitu sebesar 8 persen dari total PDB nasional. Secara nominal, pada 2016 jumlah pendapatan dari industri ekstraktif menurun sebesar 31 persen menjadi Rp 159,4 triliun dari tahun sebelumnya yang sebesar Rp 232,4 triliun. Hal ini menjadi suatu ketertarikan bahwa apakah memang Gross Domestic Product berperan dalam menambah pengaruh antara kinerja keuangan dan tingkat kebijakan utang.

\section{Rumusan Masalah}

Dari hasil latar belakang yang telah diuraikan di atas, diidentifikasi beberapa masalah utama yang dapat dijabarkan sebagai berikut:

1. Masih belum konsistennya nilai perusahaan di industri pertambangan sehingga membuat penelitian ini perlu dijalankan untuk mengetahui faktor yang dapat meningkatkan nilai perusahaan.

2. Masih sedikitnya penelitian yang menggunakan faktor makro sebagai variabel moderasi dalam penelitian.

3. Masih sedikitnya penelitian yang membahas mengenai industri pertambangan. 


\section{METODE PENELITIAN}

Subyek dalam penelitian ini adalah perusahaan pertambangan yang terdaftar di Bursa Efek Indonesia (BEI) periode 2015-2017. Desain penelitian yang digunakan dalam penelitian ini yaitu penelitian deskriptif. Penelitian deskriptif ini adalah penelitian dengan data panel, dimana data yang diperoleh lebih dari satu perusahaan serta periode waktu lebih dari satu tahun. Dalam penelitian ini program yang akan digunakan untuk mengolah data yaitu Software Eviews 9.0.

Variabel dependen dalam penelitian ini adalah nilai perusahaan. Variabel independent dalam penelitian ini adalah kinerja keuangan dan tingkat kebijakan utang, dan variabel moderator dalam penelitian ini adalah gross domestic product.

\section{Populasi, Teknik Pemilihan Sampel, dan Ukuran Sampel}

Populasi yang diambil dalam penelitian ini adalah seluruh perusahaan pertambangan yang terdaftar di BEI periode 2015-2017. Selanjutnya metode pengambilan sampel yang digunakan dalam penelitian ini adalah metode non-probability sampling dengan pendekatan purposive sampling. Menurut Sudaryono (2017), pendekatan purposive sampling adalah pendekatan dimana tidak semua populasi memiliki kesempatan yang sama untuk menjadi sampel.

Operasional Variabel dan Instrumen

\begin{tabular}{ccc}
\hline Variabel & Rumus & Jenis Data \\
\hline Kinerja Keuangan & $\begin{array}{c}\text { Retained Earnings }=\text { Total Laba ditahan } \\
\text { perusahaan }\end{array}$ & Rasio \\
\hline Tingkat Kebijakan Utang & Leverage $=\frac{\text { Total Hutang }}{\text { Total Ekuitas }}$ & Rasio \\
\hline Nilai Perusahaan & Tobin's Q $=\frac{\text { Nilai Pasar Ekuitas +Total Hutang }}{\text { Total Aset }}$ & Rasio \\
\hline Gross Domestic Bruto & $\begin{array}{c}\text { Gross Domestic Product }=\text { Laba Domestik } \\
\text { Tahunan }\end{array}$ & Rasio \\
\hline
\end{tabular}

\section{Teknik Pengumpulan Data}

Penelitian ini menggunakan sumber data yang berfokus pada data sekunder. Data sekunder merupakan data yang dapat diambil atau diperoleh dari lembaga pengumpul data atau dari media perantara (tidak langsung) berupa arsip yang dipublikasikan secara umum, yang dapat diakses dengan mudah oleh masyarakat pengguna dengan tujuan untuk mempermudah pengguna dalam menyelesaikan masalah yang dihadapi. Lembaga pengumpul data yang dimaksud adalah Bursa Efek Indonesia (BEI). Insdustri yang digunakan dalam penelitian ini adalah industri pertambangan yang terdaftar di BEI tahun 2015-2017.

\section{Analisis Data}

Data-data yang telah diperoleh dan dikumpulkan tersebut akan diproses, diolah kemudian akan dianalisis untuk menentukan jawaban dari rumusan masalah yang telah ditentukan pada bab 1 . Software yang akan digunakan pada penelitian ini untuk mengolah data adalah EVIEWS (Econometric Views) versi 9.0 untuk windows

\section{HASIL DAN PEMBAHASAN}

\section{Deskripsi Subjek Penelitian}

Perusahaan yang dapat memenuhi kriteria dalam penelitian pada periode 2015-2017 adalah sebanyak 34 perusahaan. Perusahaan pertambangan sendiri merupakan semua perusahaan yang kegiatannya mengelola dan meneliti setiap sumber daya alam seperti mineral, batubara, minyak 
bumi dan lain-lain. Perusahaan pertambangan di Bursa Efek Indonesia dipilih sebagai subjek penelitian karena penelitan terhadap perusahaan pertambangan masih sedikit

Tabel 1. Proseksi Seleksi Sampel

Sumber : Hasil pengolahan sampel

\begin{tabular}{|l|l|l|l|l|}
\hline Kriteria seleksi sampel & 2015 & 2016 & 2017 & Total \\
\hline $\begin{array}{l}\text { Perusahaan pertambangan yang } \\
\text { terdaftar di IDX pada tahun 2015 -2017 }\end{array}$ & 41 & 41 & 41 & 41 \\
\hline Pengurangan: & & & & \\
\hline $\begin{array}{l}\text { Perusahaan yang tidak IPO selama } \\
\text { tahun 2015 - 2017 }\end{array}$ & $(0)$ & $(0)$ & $(3)$ & 38 \\
\hline $\begin{array}{l}\text { Perusahaan yang menggunakan dollar } \\
\text { sebagai mata uang dasar di laporan } \\
\text { keuangan }\end{array}$ & $(23)$ & $(23)$ & $(23)$ & 15 \\
\hline $\begin{array}{l}\text { Perusahaan yang delisting dan relisting } \\
\text { selama tahun 2015-2017 }\end{array}$ & $(1)$ & $(1)$ & $(0)$ & 13 \\
\hline
\end{tabular}

\section{Statistik Deskriptif}

Analisis statistik deskriptif dilakukan pada saat sebelum melakukan pengujian data untuk memberikan gambaran mengenai data yang dilakukan dengan menggunakan program software Eviews 9.0. Berikut ini merupakan tabel analisis statistik deskriptif:

Tabel 2. Hasil Uji Statistik Deskriptif

Sumber : Pengolahan data dengan menggunakan Eviews 9.0

RE TOBINSQ LEV GDPRE GDPLEV GDP

$\begin{array}{lcccccc}\text { Mean } & 474.0343 & 0.447795 & 0.945667 & 2373.457 & 4.734310 & 5.000000 \\ \text { Median } & 1.813000 & 0.450000 & 0.819000 & 8.885316 & 4.013097 & 5.000000 \\ \text { Maximum } & 5811.177 & 0.691000 & 2.226000 & 29637.00 & 10.90787 & 5.100000 \\ \text { Minimum } & -361.1750 & 0.029000 & 0.024000 & -1769.759 & 0.120585 & 4.900000 \\ \text { Std. Dev. } & 1375.692 & 0.170607 & 0.527082 & 6905.669 & 2.647741 & 0.082717 \\ \text { Skewness } & 3.048556 & -1.145455 & 0.307173 & 3.072958 & 0.305340 & 0.000000 \\ \text { Kurtosis } & 10.95519 & 3.994552 & 2.880256 & 11.16320 & 2.811330 & 1.500000 \\ & & & & & & \\ \text { Jarque-Bera } & 163.2471 & 10.13577 & 0.636608 & 169.6663 & 0.663855 & 3.656250 \\ \text { Probability } & 0.000000 & 0.006296 & 0.727382 & 0.000000 & 0.717539 & 0.160715 \\ & & & & & & \\ \text { Sum } & 18487.34 & 17.46400 & 36.88100 & 92564.82 & 184.6381 & 195.0000 \\ \text { Sum Sq. Dev. } & 71916035 & 1.106052 & 10.55697 & 1.81 \mathrm{E}+09 & 266.4001 & 0.260000 \\ \text { Observations } & 39 & 39 & 39 & 39 & 39 & 39\end{array}$

\section{Pemilihan Metode Estimasi}

Pemilihan metode estimasi dalam penelitian ini diawali dengan tahap membandingkan common effect model dengan fixed effect model. Hasil pengujian metode estimasi dengan menggunakan common effect model dapat dilihat pada tabel 4.4 sebagai berikut: 
Dependent Variable: TOBINSQ

Method: Panel Least Squares

Date: 01/14/19 Time: $12: 43$

Sample: 20152017

Periods included: 3

Cross-sections included: 13

Total panel (balanced) observations: 39

\begin{tabular}{crcrr}
\hline \hline \multicolumn{1}{c}{ Variable } & Coefficient & Std. Error & t-Statistic & Prob. \\
\hline C & -0.296376 & 1.364408 & -0.217219 & 0.8294 \\
RE & 0.000159 & 0.000477 & 0.333681 & 0.7407 \\
LEV & 0.739443 & 1.203933 & 0.614190 & 0.5433 \\
GDP & 0.090572 & 0.273642 & 0.330987 & 0.7427 \\
GDPRE & $-3.03 \mathrm{E}-05$ & $9.51 \mathrm{E}-05$ & -0.318247 & 0.7523 \\
GDPLEV & -0.086934 & 0.240921 & -0.360841 & 0.7205 \\
\hline \hline & 0.877307 & Mean dependent var & & 0.447795 \\
R-squared & 0.858717 & S.D. dependent var & & 0.170607 \\
Adjusted R-squared & 0.064127 & Akaike info criterion & & -2.515267 \\
S.E. of regression & 0.135705 & Schwarz criterion & & -2.259334 \\
Sum squared resid & 55.04771 & Hannan-Quinn criter. & & -2.423441 \\
Log likelihood & 47.19291 & Durbin-Watson stat & & 0.735921 \\
F-statistic & 0.000000 & & \\
Prob(F-statistic) & \multicolumn{3}{l}{} \\
\hline \hline
\end{tabular}

Tabel 4. Lagrange Multiplier

Sumber: Pengolahan data menggunakan Eviews 9.0

Lagrange multiplier (LM) test for panel data

Date: 01/14/19 Time: 12:01

Sample: 20152017

Total panel observations: 39

Probability in ()

\begin{tabular}{lccc}
\hline \hline $\begin{array}{l}\text { Null (no rand. effect) } \\
\text { Alternative }\end{array}$ & $\begin{array}{c}\text { Cross-section } \\
\text { One-sided }\end{array}$ & $\begin{array}{c}\text { Period } \\
\text { One-sided }\end{array}$ & Both \\
\hline \hline Honda & 3.704567 & -1.181873 & 1.783814 \\
& $(0.0001)$ & $(0.8814)$ & $(0.0372)$ \\
King-Wu & 3.704567 & -1.181873 & 0.305993 \\
SLM & $(0.0001)$ & $(0.8814)$ & $(0.3798)$ \\
& 3.922979 & -0.601173 & - \\
& $(0.0000)$ & $(0.7261)$ & -
\end{tabular}


GHM

$\begin{array}{lll}-- & - & 13.72381 \\ -- & -- & (0.0004)\end{array}$

Tabel 5. Fixed Effect

Sumber: Pengolahan data menggunakan Eviews 9.0

Dependent Variable: TOBINSQ

Method: Panel Least Squares

Date: 01/14/19 Time: 12:46

Sample: 20152017

Periods included: 3

Cross-sections included: 13

Total panel (balanced) observations: 39

\begin{tabular}{crrrr}
\hline \hline Variable & Coefficient & Std. Error & t-Statistic & Prob. \\
\hline \hline C & -0.872258 & 0.934796 & -0.933100 & 0.3614 \\
RE & 0.000186 & 0.001433 & 0.129619 & 0.8981 \\
LEV & 1.118744 & 0.811396 & 1.378789 & 0.1825 \\
GDP & 0.214361 & 0.188612 & 1.136519 & 0.2685 \\
GDPRE & $-3.83 \mathrm{E}-05$ & 0.000251 & -0.152616 & 0.8802 \\
GDPLEV & -0.170435 & 0.163026 & -1.045448 & 0.3077 \\
\hline \hline
\end{tabular}

Effects Specification

Cross-section fixed (dummy variables)

\begin{tabular}{lllr}
\hline \hline R-squared & 0.968481 & Mean dependent var & 0.447795 \\
Adjusted R-squared & 0.942965 & S.D. dependent var & 0.170607 \\
S.E. of regression & 0.040744 & Akaike info criterion & -3.258964 \\
Sum squared resid & 0.034862 & Schwarz criterion & -2.491166 \\
Log likelihood & 81.54980 & Hannan-Quinn criter. & -2.983485 \\
F-statistic & 37.95631 & Durbin-Watson stat & 2.168440 \\
Prob(F-statistic) & 0.000000 & & \\
\hline \hline
\end{tabular}


Redundant Fixed Effects Tests

Equation: Untitled

Test cross-section fixed effects

Effects Test

Statistic

d.f.

Prob.

Cross-section F

5.062078

$(12,21)$

0.0006

Cross-section Chi-square

53.004178

12

0.0000

Tabel 7. Random Effect

Sumber: Pengolahan data menggunakan Eviews 9.0

Dependent Variable: TOBINS

Method: Panel EGLS (Cross-section random effects)

Date: 02/08/19 Time: 08:57

Sample: 20152017

Periods included: 3

Cross-sections included: 13

Total panel (balanced) observations: 39

Swamy and Arora estimator of component variances

\begin{tabular}{crrrr}
\hline \hline Variable & Coefficient & Std. Error & t-Statistic & Prob. \\
\hline \hline C & 0.248165 & 0.435914 & 0.569299 & 0.5730 \\
LEV & 0.182254 & 0.063433 & 2.873189 & 0.0071 \\
RE & 0.000104 & 0.000309 & 0.336271 & 0.7388 \\
GDP & -0.019129 & 0.089068 & -0.214764 & 0.8313 \\
GDPLEV & 0.026180 & 0.014111 & 1.855297 & 0.0725 \\
GDPRE & $-1.95 \mathrm{E}-05$ & $6.10 \mathrm{E}-05$ & -0.319845 & 0.7511 \\
\hline \hline
\end{tabular}

Effects Specification

S.D. Rho 
Weighted Statistics

\begin{tabular}{llll} 
R-squared & 0.839154 & Mean dependent var & 0.159506 \\
Adjusted R-squared & 0.814783 & S.D. dependent var & 0.085552 \\
S.E. of regression & 0.036819 & Sum squared resid & 0.044735 \\
F-statistic & 34.43303 & Durbin-Watson stat & 1.474300 \\
Prob(F-statistic) & 0.000000 & & \\
\hline \hline
\end{tabular}

Unweighted Statistics

R-squared

0.883446 Mean dependent var

0.447795

Sum squared resid

0.128915 Durbin-Watson stat

0.612985

Tabel 8. Hausmann

Sumber: Pengolahan data menggunakan Eviews 9.0

Correlated Random Effects - Hausman Test

Equation: Untitled

Test cross-section random effects

Test Summary

Chi-Sq. Statistic

Chi-Sq. d.f.

Prob.

Cross-section random

0.358813

\section{Hasil Analisis Data}

Hipotesis dalam penelitian ini diuji dengan menggunakan uji determinasi ganda (uji R-squared), uji t (uji Parsial), dan uji F untuk membuktikan hipotesis hipotesis yang telah diuraikan pada bab sebelumnya

\section{Uji R-squared Sebelum Moderasi}

Tabel 9. Hasil Pengujian Determinasi Ganda (Adjusted R-squared)

Sumber: Pengolahan data menggunakan Eviews 9.0

\section{R-squared}

Adjusted R-squared

S.E. of regression
0.825823 Mean dependent var

0.177745

0.816147 S.D. dependent var

0.089914

0.038554 Sum squared resid

0.053510 


\section{Uji f Sebelum Moderasi}

Tabel 10. Hasil Pengolahan Uji F

Sumber: Pengolahan data menggunakan Eviews 9.0

$\begin{array}{llll}\text { R-squared } & 0.825823 & \text { Mean dependent var } & 0.177745 \\ \text { Adjusted R-squared } & 0.816147 & \text { S.D. dependent var } & 0.089914 \\ \text { S.E. of regression } & 0.038554 & \text { Sum squared resid } & 0.053510 \\ \text { F-statistic } & 85.34319 & \text { Durbin-Watson stat } & 1.407242 \\ \text { Prob(F-statistic) } & 0.000000 & \end{array}$

Uji t Sebelum Moderasi

Tabel 11. Hasil Pengolahan Uji t

Sumber: Pengolahan data menggunakan Eviews 9.0

Variable

t-Statistic

Prob. Coefficient

Std. Error

\begin{tabular}{ccccc}
\hline \hline C & 5.893952 & 0.0000 & 0.166337 & 0.028222 \\
RE & 0.517236 & 0.6082 & 0.000005 & $1.14 \mathrm{E}-05$ \\
LEV & 12.73165 & 0.0000 & 0.294675 & 0.023145 \\
\hline \hline
\end{tabular}

\section{Uji R-squared Sesudah Moderasi}

Tabel 12. Hasil Pengujian Determinasi Ganda (Adjusted R-squared Sumber: Pengolahan data menggunakan Eviews 9.0

R-squared

Adjusted R-squared

S.E. of regression

F-statistic

Prob(F-statistic)
0.839154 Mean dependent var

0.159506

0.814783 S.D. dependent var

0.085552

0.036819 Sum squared resid

0.044735

34.43303

Durbin-Watson stat

0.000000 


\section{Uji f Sesudah Moderasi}

Tabel 13. Hasil Pengolahan Uji F

Sumber: Pengolahan data menggunakan Eviews 9.0

\begin{tabular}{llll} 
R-squared & 0.839154 & Mean dependent var & 0.159506 \\
Adjusted R-squared & 0.814783 & S.D. dependent var & 0.085552 \\
S.E. of regression & 0.036819 & Sum squared resid & 0.044735 \\
F-statistic & 34.43303 & Durbin-Watson stat & 1.474300 \\
Prob(F-statistic) & 0.000000 & & \\
\hline
\end{tabular}

Uji t Sesudah Moderasi

Tabel 14. Hasil Pengolahan Uji t

Sumber: Pengolahan data menggunakan Eviews 9.0

\begin{tabular}{ccccr}
\hline \hline Variable & Coefficient & Std. Error & t-Statistic & Prob. \\
\hline \hline C & 0.278954 & 0.565814 & 0.132213 & 0.2323 \\
LEV & 0.182254 & 0.063433 & 2.873189 & 0.0071 \\
RE & 0.000104 & 0.000309 & 0.336271 & 0.7388 \\
GDP & -0.019129 & 0.089068 & -0.214764 & 0.8313 \\
GDPLEV & 0.221512 & 0.021301 & 1.956752 & 0.0225 \\
GDPRE & -0.002903 & 0.000963 & -0.451225 & 0.8523 \\
\hline \hline
\end{tabular}

\section{Pembahasan}

Dari hasil uji hipotesis di atas maka dapat dibentuk pembahasan adalah melihat dari hasil uji deskriptif, ditemukan bahwa rata-rata tingkat hutang mendekati nilai 1 (0.945), Dengan keadaan ini, dapat diartikan bahwa mayoritas perusahaan pertambangan terfokus pada kebutuhan dari manajemen dibandingkan agen. Selanjutnya, dari hasil uji deskriptif juga ditemukan nilai Tobins' $Q$ sudah cukup tinggi (0.44 dari maximum 0.69) hal ini berarti perusahaan pertambangan sudah menggunakan Tobins'Q sebagai salah satu medium untuk memberikan signal kepada investor. Untuk pengaruh tingkat kebijakan utang terhadap nilai perusahaan, ditemukan bahwa tingkat kebijakan utang berpengaruh positif signifikan terhadap nilai perusahaan pertambangan yang terdaftar di BEI periode 2015-2017. Untuk Pengaruh kinerja keuangan terhadap nilai perusahaan, ditemukan bahwa kinerja keuangan tidak berpengaruh terhadap nilai perusahaan pertambangan yang terdaftar di BEI periode 2015-2017. Untuk peranan Gross Domestic Product dalam memperlemah pengaruh kinerja keuangan terhadap nilai perusahaan, ditemukan bahwa memang gross domestic product tidak memoderasi pengaruh kinerja keuangan terhadap nilai perusahaan pertambangan yang terdaftar di BEI periode 2015-2017. Untuk peranan Gross 
Domestic Product dalam memperkuat pengaruh tingkat kebijakan utang terhadap nilai perusahaan, ditemukan bahwa memang gross domestic product memperkuat pengaruh tingkat kebijakan utang terhadap nilai perusahaan pertambangan yang terdaftar di BEI periode 20152017.

\section{KESIMPULAN DAN SARAN}

Sesuai dengan teori dan pembahasan yang telah dijelaskan sebelumnya, tujuan dalam penelitian ini yaitu untuk menguji pengaruh kinerja keuangan dan tingkat kebijakan utang terhadap nilai perusahaan dengan Gross Domestic Product sebagai variabel moderator pada perusahaan Pertambangan yang terdaftar di BEI periode 2015-2017. Dari total 13 perusahaan Pertambangan yang terdaftar di Bursa Efek Indonesia pada tahun 2015 sampai dengan 2017, hanya terdapat 13 perusahaan yang memenuhi kriteria yang telah ditetapkan dalam penelitian ini sehingga dapat disimpulkan bahwa dalam penelitian ini terdapat 13 perusahaan atau 39 data yang digunakan. Pengolahan data atas data yang telah dilampirkan dalam penelitian ini menggunakan software Eviews versi 10.0. Penggunaan Eviews versi 10.0 dapat menghasilkan model manakah yang paling tepat untuk digunakan dalam penelitian ini yaitu menggunakan Uji Chow dan Uji Hausman. Dan selanjutnya dilakukan uji multikolinearitas untuk dapat mengetahui apakah model regresi terdapat hubungan (korelasi) antar variabel independen. Berikutnya dilakukan Uji $\mathrm{t}$, Uji $\mathrm{F}$, uji ini digunakan untuk dapat mengetahui tingkat signifikan, pengaruh masing-masing variabel independen terhadap variabel dependen.

Dalam penelitian ini, diperoleh beberapa saran yang dapat diberikan untuk peneliti selanjutnya. Yaitu, periode penelitian diharapkan lebih dari 3 tahun atau sebanyak-banyaknya agar penelitiannya mendapatkan hasil yang lebih akurat, lebih luas, terpercaya, dan mampu untuk menggambarkan keadaan dengan lebih jelas. Menambahkan jumlah variabel independen yang dapat digunakan yang dapat mempengaruhi nilai perusahaan seperti praktik manajemen laba, Good Corporate Governance, Risiko bisnis, dan sebagainya. Kemudian Diharapkan tidak hanya terfokus pada perusahaan pertambangan melainkan mencoba untuk melaksanakan penelitian terhadap sektor-sektor lain yang terdapat didalam pasar modal seperti perusahaan manufaktur agar dapat memperluas pengetahuan dan juga bisa lebih mengetahui kondisi perusahaan tersebut lebih luas.

\section{Ucapan Terima Kasih}

Adapun ucapan terima kasih ini saya tujukan pertama-tama kepada Tuhan Yang Maha Esa serta Keluarga saya dan sejumlah nama dibawah ini:

1. Segenap Bapak dan Ibu Dosen, serta Staf di Fakultas Ekonomi Magister Akuntansi Universitas Tarumanegara yang telah memberikan banyak ilmu sehingga dapat diterapkan di dalam tesis ini serta banyak memberikan bantuan dan dukungan dari awal hingga selesainya proses pengerjaan tesis ini.

\section{REFERENSI}

Ahmed, Farhan., Awais, Iqra., Kashif, Muhammad. (2018). Financial Leverage and Firms' Performance: Empirical Evidence from KSE-100 Index. Etikonomi Volume 17 (1), 2018 : 45 - 56 P-ISSN: 1412-8969; E-ISSN: 2461-0771

Ater, Daniel Kon., Kisaka. E Sifunjo., Mwangi, Mirie. (2018). The Moderating effect of Macroeconomic Factors on the Relationship between Capital Structure and Value of nonfinancial firms listed at the Nairobi Securities Exchange. International J. Soc. Sci. \& Education 2017 Vol.7 Issue 3, ISSN: 2223-4934 E and 2227-393X Print

Fahmi, Irham. (2012). Analisis Kinerja Keuangan. CV Alfabeta: Bandung. 
Horne, C. V. James dan Wachowicz, M. John. (2009). Prinsi-prinsip Manajemen Keuangan, Edisi 11. Jakarta: Salemba Empat.

Jiraporn, P., Kim, Y., \& Kim, J. (2011). Dividend Policy and Corporate Governance Quality: Evidence From ISS. The Financial Review. 46, 251-279. http://dx.doi.org/10.1111/j.1540-6288.2011.00299.x

Jogiyanto, (2014).Teori Portofolio dan Analisis Investasi, Edisi ke 10. Yogyakarta: BPFE.

Kasmir. (2012). Analisis Laporan Keuangan. Jakarta: PT. Raja Grafindo Persada.

Mankiw, N. Gregory. (2012). Macroeconomics. New York: Harvard University

Pratiwi, Diah A. (2010). Analisis Pengaruh Earning Management terhadap Nilai Perusahaan dengan Peranan Praktik Corporate Governance sebagai Moderating Variabel pada Perusahaan yang Terdaftar Di Bursa Efek Indonesia Periode 2005-2008. Skripsi. Universitas Diponegoro. Semarang.

Riyanto, Bambang. (2011). Dasar - Dasar Pembelanjaan Perusahaan Edisi Keempat, Cetakan Ketujuh. Yogyakarta: YBPFE UGM

Scott, W. R. (2012). Financial Accounting Theory 6th edition. Toronto: Pearson Education

Singh, Satwinder., Tabassum, Naeem., Darwish, K. Tamer., Batsakis, Gerogios. (2018). Corporate Governance and Tobin's Q as a Measure of Organizational Performance. British Journal of Management, Vol. 29, 171-190 (2018)

Sudaryono (2017). Metodologi Penelitian. Jakarta: Rajawali Press.

Sudiyanto, Bambang dan Elen, Puspitasari. (2010). Tobin's Q dan Altman Z-score Sebagai Indikator Pengukur Kinerja Perusahaan. Jurnal Kajian Akuntansi. Vol. 2, No. 1. februari : 9-21.

Sugiyono. (2014). Metode Penelitian Pendidikan Pendekatan Kuantitatif, Kualitatif Dan R\&D. Bandung: Alfabeta

Suharli, Michell. (2010). Studi Empiris Mengenai Pengaruh Profitabilitas, Leverage, dan Harga Saham terhadap Jumlah Dividen Tunai (Studi pada Perusahaan yang Terdaftar di Bursa Efek Jakarta Periode 2002-2003)”. JURNAL MANAJEMEN, AKUNTANSI \& SISTEM INFORMASI , 6 (2), 243-256.

Suwardjono. (2010). Teori Akuntansi: Pengungkapan dan Sarana Interpretatif. Edisi Ketiga. BPFE, Yogyakarta.

Thaib, Chaidir dan Taroreh, Rita. (2015). Pengaruh kebijakan hutang dan profitabilitas terhadap kebijakan dividen (studi pada perusahaan foods and beverages yang terdaftar di bei tahun 2010-2014). Jurnal EMBA, Volume 3, Nomor 4, Desember 2015: 215-225.

Weston, J. Fred dan Copeland, Thomas E. (2008). Manajemen Keuangan, Penerjemah: A. Jaka Wasana. Binarupa Aksara: Jakarta.

Wibowo. (2012). Manajemen Kinerja. Jakarta: PT Raja Grafindo Persada.

Wira, Winata. (2011). Pengaruh PDB Sektor, Nilai Tukar Dan Indeks Harga Rodusen Terhadap Penjaman Perbankan. JEMI, Vol. 2, No.2, Desember 2011

Yemi, Akinkoye Ebenezer dan Seriki, Akinadewo Israel. (2018). Retained earnings and Firms' Market Value: Nigeria Experience. International Journal of Business and Economic Development. ISSN 2051-848X (Print) ISSN 2051-8498 (Online). Volume 6 Number 2 July 2018

https://ekonomi.kompas.com/read/2018/11/06/060700626/bi--permintaan-domestik-topangpertumbuhan-ekonomi-di-kuartal-iii-2018 